\title{
Breaking the fragility fracture cycle
}

\author{
C. Cooper $\cdot$ P. Mitchell $\cdot$ J. A. Kanis
}

Received: 21 February 2011 / Accepted: 13 April 2011 /Published online: 24 May 2011

(C) International Osteoporosis Foundation and National Osteoporosis Foundation 2011

Fracture begets fracture. This phenomenon has been wellcharacterised in many prospective studies and summarised by meta-analyses $[1,2]$; a prior fracture at least doubles a patient's future fracture risk. Elevated fracture risk persists for up to 10 years after the initial fracture event [3] and is greatest during the first year after this [4]. Several studies have explored this phenomenon from the obverse view of fracture history in patients presenting to hospital with a hip fracture. In 1980, Gallagher and colleagues reported prior fracture history amongst patients presenting with hip fracture in Rochester, USA for the period 1965-1974 [5]. Sixty-eight percent of women and $59 \%$ of men had suffered at least one other fracture besides their hip fracture. More recent studies from the UK [6], USA [7] and Australia [8]

Related articles can be found at doi:10.1007/s00198-011-1534-0, doi:10.1007/s00198-011-1544-y, doi:10.1007/s00198-011-1638-6 and doi:10.1007/s00198-011-1642-x.

\section{Cooper $(\bowtie)$}

MRC Lifecourse Epidemiology Unit, University of Southampton,

Southampton General Hospital,

Southampton SO16 6YD, UK

e-mail: cc@mrc.soton.ac.uk

\section{Cooper}

NIHR Musculoskeletal Biomedical Research Unit, Institute of Musculoskeletal Sciences, University of Oxford,

Oxford OX3 7LD, UK

P. Mitchell

School of Health, Faculty of Education, Health and Sciences, University of Derby,

Derby, UK

\section{J. A. Kanis}

Centre for Metabolic Bone Diseases (WHO Collaborating

Centre), University of Sheffield Medical School,

Beech Hill Road,

Sheffield S10 2RX, UK have consistently reported that $45 \%$ or more of today's hip fracture patients have a prior fracture history.

These epidemiological data reveal a stark truth; almost half of hip fracture patients provide us with an obvious opportunity for preventive intervention. Tragically, numerous studies from across the world have found that healthcare systems are failing to respond to the first fracture to prevent the second $[9,10]$. This special issue of Osteoporosis International focuses on post-fracture coordinatorbased models that have been shown to close the secondary prevention management gap.

The systematic review conducted by Sale and colleagues [11] considered published models of case-finding systems in the orthopaedic environment. The reviewers sought to evaluate the structure, protocols, staffing and outcomes of different models and categorise them by the key elements present in each program. Sixty-five percent formally described the role of a dedicated coordinator who identified patients, facilitated BMD testing and the initiation of osteoporosis treatment. A clear message is that coordinator-based models circumvent the challenge of where clinical responsibility resides for osteoporosis care of the fragility fracture patient.

The Glasgow Fracture Liaison Service (FLS) has provided clinically effective post-fracture osteoporosis care for the one million residents of Glasgow, Scotland for the last decade [12]. McLellan and colleagues' formal costeffectiveness analysis of the Glasgow FLS [13] provides crucial health economic information in the prevailing austere economic climes. An estimated 18 fractures were prevented, including 11 hip fractures, and $£ 21,000$ $(€ 23,350$, US $\$ 34,700)$ was saved per 1,000 patients managed by the FLS versus "usual care" for the United Kingdom. To date, approximately one third of the UK's 61 million residents are served by an FLS. McLellan has 
estimated that universal access for the UK could be achieved at a cost of $£ 9.7$ million ( $€ 10.8$ million, US $\$ 16$ million), which represents $0.6 \%$ of the $£ 1.7$ billion ( $€ 1.9$ billion, US $\$ 2.8$ billion) [14] estimated annual cost of hip fracture care alone to the UK economy.

In response to the emerging evidence on the clinical and cost-effectiveness of coordinator-based models of care, the Fracture Working Group of the International Osteoporosis Foundation (IOF) has published an IOF Position Paper [15] in this issue. The Position Paper summarises the clinical and cost-effectiveness case for coordinator models, considers practical experience that is transferable between healthcare systems and describes steps to achieve consensus amongst professionals, patients and policymakers. Sharing of best practice to drive change at a national level is intended to support colleagues to make fragility fracture prevention a political priority across the world.

Half of hip fracture patients give us considerable advance notice that one day they will visit their local orthopaedic unit. Harrington has previously described osteoporosis care of fragility fracture patients as “... a Bermuda Triangle comprised of orthopaedic surgeons, primary care physicians and osteoporosis experts, into which the fracture patient disappears" [16]. The lack of clear clinical responsibility that underpins this description can be eliminated by implementation of post-fracture coordinator-based models of care.

Over the next 20 years, 450 million people will celebrate their 65th birthday [17]. On account of this, absolute hip fracture incidence will remain high and costly in the West and presents a major threat to financing of health systems in the East. Dell and colleagues have made the case that a systematic approach can translate to a $25 \%$ reduction in the incidence of hip fractures versus the expected rate [18]. This is a realistic aspiration for healthcare systems that take aggressive steps to close the secondary fracture prevention care gap. As the baby boomers begin to retire from early 2011, professional organisations, patient societies and policymakers all recognise that failure to do so is not an option.

\section{Conflicts of interest None.}

\section{References}

1. Klotzbuecher C, Ross PD, Landsman PB et al (2000) Patients with prior fractures have an increased risk of future fractures: a summary of the literature and statistical synthesis. JBMR 15:721739

2. Kanis JA, Johnell O, De Laet C et al (2004) A meta-analysis of previous fracture and subsequent fracture risk. Bone 35:375-382

3. Center JR, Bliuc D, Nguyen TV et al (2007) Risk of subsequent fracture after low-trauma fracture in men and women. JAMA 297:387-394

4. Johnell O, Kanis JA, Oden A et al (2004) Fracture risk following an osteoporotic fracture. Osteoporos Int 15:175-179

5. Gallagher JC, Melton LJ, Riggs BL et al (1980) Epidemiology of fractures of the proximal femur in Rochester, Minnesota. Clin Orthop Relat Res 150:163-171

6. McLellan AR, Reid DM, Forbes K et al (2004) NHS Quality Improvement Scotland. Effectiveness of strategies for the secondary prevention of osteoporotic fractures in Scotland. http://www.nhshealthquality.org/nhsqis/qis_display_findings. jsp?pContentID $=2755 \& p \_$applic $=C C C \& p E l e m e n t I D=0 \& p M e$ nuId $=0 \& p$ service $=$ Content. show\& Accessed 31 January 2011

7. Edwards BJ, Bunta AD, Simonelli C et al (2007) Prior fractures are common in patients with subsequent hip fractures. Clin Orthop Relat Res 461:226-230

8. Port L, Center J, Briffa NK et al (2003) Osteoporotic fracture: missed opportunity for intervention. Osteoporos Int 14:780-784

9. Elliot-Gibson V, Bogoch ER, Jamal SA et al (2004) Practice patterns in the diagnosis and treatment of osteoporosis after a fragility fracture: a systematic review. Osteoporos Int 15:767778

10. Giangregorio L, Papaioannou A, Cranney A et al (2006) Fragility fractures and the osteoporosis care gap: an international phenomenon. Semin Arthritis Rheum 35:293-305

11. Sale JEM, Beaton D, Posen J et al (2010) Systematic review on interventions to improve osteoporosis investigation and treatment in fragility fracture patients. Osteoporos Int. doi:10.1007/s00198011-1544-y

12. McLellan A, Gallacher S, Fraser M et al (2003) The fracture liaison service: success of a program for the evaluation and management of patients with osteoporotic fracture. Osteoporos Int 14:1028-1034

13. McLellan AR, Wolowacz SE, Zimovetz EA et al (2010) Fracture liaison services for the evaluation and management of patients with osteoporotic fracture: a cost-effectiveness evaluation based on data collected over 8 years of service provision. Osteoporos Int. doi:10.1007/s00198-011-1534-0

14. Torgerson D, Iglesias C, Reid D (2011) The economics of fracture prevention. In: Barlow D, Francis RM, Miles A (eds) The effective management of osteoporosis. Aesculapius Medical Press, London, pp 111-121

15. Marsh D, Åkesson K, Beaton DE et al (2011) Coordinator-based systems for secondary prevention in fragility fracture patients. Osteoporos Int. doi:10.1007/s00198-011-1642-x

16. Harrington JT (2006) Dilemmas in providing osteoporosis care for fragility fracture patients. US Musculoskeletal Review-Touch Briefings. http://www.touchbriefings.com/cdps/cditem.cfm? nid $=2162 \&$ cid $=5 \#$ Osteoporosis Accessed 31 January 2011

17. The global coalition on aging http://www.globalcoalitiononaging. $\mathrm{com} / \mathrm{v} 1 /$ Accessed 31 January 2011

18. Dell R, Greene D, Schelkun SR et al (2008) Osteoporosis disease management: the role of the orthopaedic surgeon. J Bone Joint Surg Am 90:188-194 